\title{
GROWTH INHIBITION OF PATHOGENIC ROOT FUNGI BY EXTRACTS OF ECTOMYCORRHIZAL FUNGI OR Picea glehnii INOCULATED WITH ECTOMYCORRHIZAL FUNGI*
}

\author{
MARIA CATARINA MEGUMI KASUYA \\ Dep. de Microbiologia, Universidade Federal de Vicosa, \\ Vicosa, MG, 36570-000, Brazil \\ SATOSHITAHARA \\ Dept. of Applied Bioscience, Faculty of Agriculture, \\ Hokkaido University, Kita-ku, Sapporo 060, Japan \\ and \\ TSUNEO IGARASHI \\ Dept. of Forest Science, Faculty of Agriculture, \\ Hokkaido University, Kita-ku, Sapporo 060, Japan
}

\begin{abstract}
This work sought to verify the presence of compounds with antimicrobial properties in extracts of ectomycorrhizal fungi or in Picea glehnii inoculated with ectomycorrhizal fungi. Extracts from Pisolithus tinctorius, Scleroderma flavidum, Amanita pantherina and Paxillus sp., grown in liquid culture media, and from $P$. glehnii seedlings inoculated or not with the above ectomycorrhizal fungi and cultivated in in vitro condition, were processed to obtain two fractions, water and ethyl acetate solubles. These fractions were tested for the presence of inhibitory constituents against Fusarium roseum, Pythium sp. and Rhizoctonia solani. Direct bioautography technique on TLC or paper disc technique was used, depending on the extract and pathogenic fungi tested. The results showed the production on inhibitory components, not only by ectomycorrhizal fungi, but also by $P$. glehnii inoculated or not with ectomycorrhizal fungi. The sensitivity varied considerably according to the type of fungus or extract.
\end{abstract}

Key words: Japan/Mycorrhizas/Inh/bition/Extracts/Antimicrobial compounds/Amanita pantherina/Pisolithus tinctorius/Paxillvs spJScleroderma flavidum/Fusarium roseum/Pythium $\mathrm{spJRhizoctonia} \mathrm{solani.}$

\section{INTRODUCTION}

Damping-off has been responsible for considerable losses of tree species in nurseries. Research has shown that these losses can be reduced by inoculation of effective

\footnotetext{
* Paper presented at the Second Symposium on Biology and Biotechnology of Mycorrhizae and Third Asian Conference on Mycorrhizae (ACOM III), 19 - 21 April 1994, Yogyakarta, Indonesia
} 
ectomycorrhizal fungi (Sinclair et al 1982, Chakravarty and Unestan 1987; Sampangi et al. 1985; Duchesne et al. 1989). It has been postulated that root protection by ectomycorrhizal fungi results from antibiotic synthesis which could either be by the myco-symbiont or by the host plant; a barrier effect caused by the presence of a fungal mantle around roots; or a nutrient competition in the rhizosphere (Zak 1964; and Marx 1973). None of these can be viewed as universal mechanism (Harley and Smith 1983), but several mechanisms may act simultaneously and/or synergistically to suppress disease (Schisler and Linderman 1987).

The synthesis of antimicrobial substances by plants in response to ectomycorrhizal fungi has been reviewed and the use of ectomycorrhizal fungi in biological control has been reported (Duchesne et al. 1987: 1989b). Since the protection provided by these fungi is also influenced by environmental conditions including tree species and pathogens involved (Marx 1969; Stack and Sinclair 1975; Sylvia and Sinclair 1983a,b; Perrin and Garbaye 1983; Sampangi and Perrin 1986; Chakravarty and Unestan 1987a,b; Duchesne et al. 1989), a screening of ectomycorrhizal fungi that is able to produce antimicrobial substances is useful for a better understanding of the mechanism of disease suppression by ectomycorrhizal association.

A better understanding of involved mechanisms may lead not only to field manipulations of environmental conditions to enhance disease protection, but also help the design of optimal screening programs. It may also favour the discovery of new pesticides which lead to novel methods of disease control (Duchesne et al. 1989b).

This study sought to verify the presence of compounds possessing antimicrobial properties in the extracts of ectomycorrhizal fungi or in P. glehnii inoculated with ectomycorrhizal fungi.

\section{MATERIALS AND METHODS Fungal}

\section{Cultures}

The ectomycorrhizal fungi, Pisolithus tinctorius (Pers.) Coker \& Couch, Scleroderma flavidum E.\&E., Amanita pantherina (DC.:Fr.) Krombh. and Paxillus sp., were isolated from basidiocarps collected under different forest species in Hokkaido. All of them were proven to be mycorrhizal fungi by in vitro condition with $P$. glehnii (unpublished data). The phytopathogenic fungi, Fusarium roseum, Rhizoctonia solani and Pythium sp. were isolated from $P$. glehnii seedlings, collected from nursery beds, and kindly provided by Y.Y. Cha, of Lab. of Sylviculture, Fac. of Agriculture, Hokkaido University. The ectomycorrhizal fungi were maintained on Modified Melin Norkran 
(MMN) solution a (Kottke et al. 1987) and the pathogenic fungi on PDA (Potato Dextrose Agar), both on Petri dishes at $26^{\circ} \mathrm{C}$ in the dark.

\section{Extracts from ectomycorrhizal fungi}

The ectomycorrhizal fungi were grown in $\mathrm{MMN}$ at $16^{\circ} \mathrm{C}$, in the dark. After 34 days, a volume of $90 \%$ methanol $(\mathrm{MeOH})$ equal to that of growing cultures was added to each culture. This mixture was filtered after 24 hours, and the $\mathrm{MeOH}$ in the filtrate material was evaporated under vacuum condition at $40^{\circ} \mathrm{C}$. The constituents in the concentrate were partitioned between water and ethyl acetate (EtOAc). These extracts were stored in the dark at $-10^{\circ} \mathrm{C}$.

\section{In vitro seedlings cultivation}

The growth system for the in vitro seedlings cultivation consisted of a modified method of Sylvia and Sinclair (1983a) and Duchesne et al (1988a). The test tubes (200 x $30 \mathrm{~mm})$ were lined with filter paper (100 x $100 \mathrm{~mm})$, immersed in MMN solution a (Kottke et al. 1987). Seeds of $P$. glehnii were superficially disinfested for 30 min. in $\mathrm{H}_{2} \mathrm{O}_{2} 30 \%$, rinsed with autoclaved distilled water, and germinated for 7 days in Petri dishes before transferring to the test tubes containing the nutrient solution. Three seedlings per tube were transferred to each tube and the roots were placed between the filter paper and test tube wall. A week after the seedlings had been transferred, they were inoculated by using one disc ( $7 \mathrm{~mm}$ diameter) containing ectomycorrhizal fungi's myce-lia. The discs were placed between filter paper and test tube wall close to the roots. Twenty-five replications per treatment were taken.

\section{Extracts from seedling}

The extraction was done on six-month-old seedling. The in vitro synthesis material was divided into two parts: (A) the liquid part, containing nutrient solution and exudates from root and fungi, and (B) the solid part, containing root systems, mycelia and filter paper. An equal volume of EtOAc was added to the liquid part, and the mixtures were shaken to yield water and EtOAc soluble fractions. To the solid part, initially about $20 \mathrm{ml}$ of $90 \% \mathrm{MeOH}$ was added per synthesis in vitro. Twenty-four hours later, the mixture was filtered. The $\mathrm{MeOH}$ of the filtrate was evaporated under vacuum condition, at $40^{\circ} \mathrm{C}$, and the constituents in the concentrate were partitioned between water and EtOAc soluble fractions. 


\section{Direct bioautography technique on TLC}

This technique was applied to EtOAc soluble fractions and pathogenic fungi, Fusarium roseum and Pythium sp. that produce large quantities of spores. The spores of Cladosporium herbarum were used as the control to verify the presence of fungitoxic substance due to its high sensibility.

Samples of EtOAc extracts equivalent to 10 and $20 \mathrm{mg}$ of mycelia or seedling (dry weight basis) were subjected to TLC using Silica Gel 60 F254 plates with a thickness of $0.25 \mathrm{~mm}$ and a mixture of chloroform-MeOH (20:1). The constituents were viewed under UV $245 \mathrm{~nm}$ (quenching) and 356nm (fluorescent) light, and then the chromatograms were sprayed with a spore suspension of $C$. herbarum, F. roseum and Pythium sp. (Romans and Fuchs 1970). The plates were incubated in a moisture chamber at $28^{\circ} \mathrm{C}$ for 5 days to detect growth inhibition spots. The relative distance $(r R f)$ of each inhibition spot was calculated as the relation between the distance of inhibition spot from the starting line and the distance of remarkable fluorescent spot presented by the extract from P. glehnii (B) from the starting line, which was detected close to the front line.

\section{Paper disc technique}

The effects of EtOAc soluble fractions on $R$. Solani, and on all water soluble fractions on Phythium, F. roseum and $R$. Solani were examined using paper disc technique. Extracts equivalent to 10 and $20 \mathrm{mg}$ (dry weight basis) of seedling material and A. pantherina, and 10 and 13.8; 10 and 16.6; and 10 and $11.8 \mathrm{mg}$ for P. tinctorius, S. flavidum and Paxillus sp., respectively, were aseptically imbibed in $8 \mathrm{~mm}$ paper discs. The smaller quantities $(<20 \mathrm{mg})$ were used since the densities of extracted fraction for those fungi exceeded the absorption capacity of the paper discs. To verify the inhibition zone produced by the extracts, two doses of each extract were placed on the same Petri dish but opposite each other, and the pathogenic fungus mycelia disc $(7 \mathrm{~mm})$ was located in the center of the dish (Fig. 1). The incubation time defined according to the growth rate of pathogenic fungi in previous assays was 3, 8 and 20 days for Pythium, F. roseum and $R$. solani, respectively. The relative inhibition radius $(r l R)$ was calculated as the relation between the radius of inhibition and the radius of paper disc (Fig. 1). There were 2 replications per treatment.

\section{RESULTSAND DISCUSSION}

Some constituents of EtOAc extract inhibited the growth of pathogenic fungi. However, these substances acted differently on the individual pathogens, as verified 


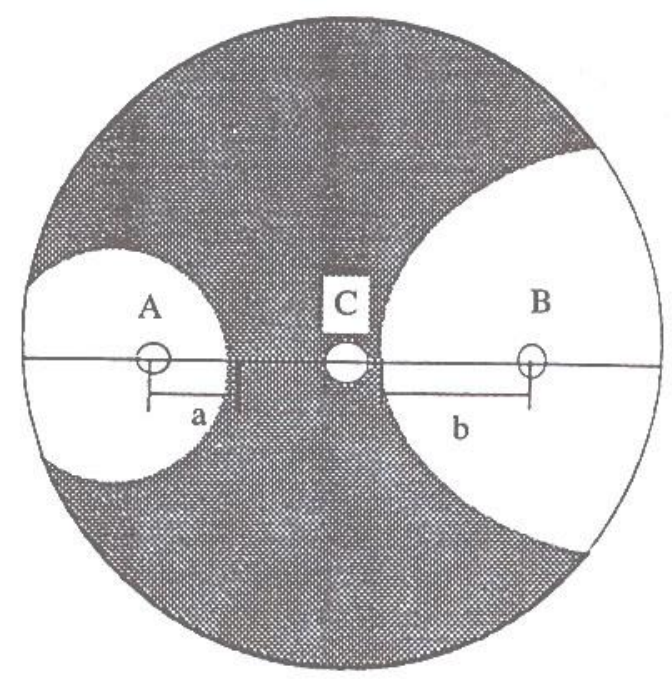

Figure 1. Scheme of the paper disc technique. A and B are $8 \mathrm{~mm}$ disc imbibed, respectively, with equivalent to 10 and $20 \mathrm{mg}$ of ectomycorrhizal fungi or $P$. glehnii extract. C is $7 \mathrm{~mm}$ containing pathogenic fungi inoculum; $\mathrm{a}$ and $\mathrm{b}$ are the radius of inhibition zone. Shaded area represents colony growth of pathogenic fungi.

from the different $\mathrm{rRf}$ on inhibition spots (Table 1), except for the extract of $A$. pantherina X P. glehnii. For this host-fungus combination the same spot inhibited both $C$. herbarum and F. roseum.

Some spots visible under UV $254 \mathrm{~nm}$ and $365 \mathrm{~nm}$ were fungitoxic, but not all fungitoxic spots were detected under UV light. The fungitoxic substances were more frequently detected in the liquid part of extracts obtained from the seedlings, suggesting that many antibiotic components are present in the exudates. Duchesne et al. (1988a) observed that fungitoxic materials were present in the rhizosphere but not in plant tissue of Pinus resinosa inoculated with $P$. involutus. In the water fractions (Table 2), fungitoxic compounds were detected in the solid materials (root system + filter paper + mycelia).

All ectomycorrhizal fungi tested were capable of producing some kind of fungitoxic substance (Table 1). Inhibition of phytopathogenic fungi by cell free culture media of ectomycorrhizal fungi was tested by Kope and Fortin (1989). The authors verified that 7 ectomycorrhizal fungi inhibited 20 out of 24 pathogenic fungi tested.

It is possible to produce fungitoxin againts Pythium when $P$. glehnii inoculated with $P$. tinctorius was synthesized by the latter, since the same spot was present in the extract of this fungus (Table 1). The presence of the host plant could have stimulated the synthesis of the fungitoxin, considering the smaller quantity of mycelia present in the 
Table 1. Inhibition spots ( $r R f^{*}$ ) against Cladosporium herbarum, Fusarium roseum and Pythium sp. when extracts equivalent to 10 and $20 \mathrm{mg}$ of mycelia or plant material (dry weight basis) was applied to direct bioautography on the TLC plates.

\begin{tabular}{|c|c|c|c|c|c|c|c|}
\hline \multirow[t]{2}{*}{ Samples } & \multirow{2}{*}{$\begin{array}{l}\text { Fungus } \\
\text { mg of material }\end{array}$} & \multicolumn{2}{|c|}{ C. herbarum } & \multicolumn{2}{|c|}{ F.roseum } & \multicolumn{2}{|c|}{ Pythium sp. } \\
\hline & & 10 & 20 & 10 & 20 & 10 & 20 \\
\hline & & ....... & ........... & $\ldots \ldots \ldots \ldots$ & $r R f$................... & ........ & ........... \\
\hline \multicolumn{2}{|c|}{ P. glehnii $(P g)\left(\mathrm{A}^{* *}\right)$} & - & - & - & - & . & - \\
\hline \multicolumn{2}{|c|}{ P. glehnii (B" $\left.{ }^{* *}\right)$} & - & - & - & - & - & - \\
\hline \multicolumn{2}{|c|}{$P$. tinctorius } & - & - & - & - & (.75) & $(.75)$ \\
\hline \multicolumn{2}{|c|}{ P. tinctorius $X P g$ (A) } & - & - & $(.41)(.58)$ & $(.41)(.58)(.65)$ & - & - \\
\hline \multicolumn{2}{|c|}{ P. tinctorius $X P_{g}(\mathrm{~B})$} & - & - & - & - & (.75) & $(.75)$ \\
\hline \multicolumn{2}{|c|}{ S. flavidum } & (.45) & $(.33)(.45)$ & - & - & (.61) & (.61) \\
\hline \multicolumn{2}{|c|}{ S. flavidum $X P g$ (A) } & - & - & - & - & - & - \\
\hline \multicolumn{2}{|c|}{ S. flavidum $X P_{g}(\mathrm{~B})$} & - & - & - & - & - & - \\
\hline \multicolumn{2}{|c|}{ A. panthrerina } & $(0)$ & $(0)(.38)(.40)$ & - & - & - & - \\
\hline \multicolumn{2}{|c|}{ A. panthrerina $X P g(\mathrm{~A})$} & $(.74)$ & $(.74)(.95)(1.0)$ & $(.74)$ & (.74) & - & - \\
\hline \multicolumn{2}{|c|}{ A. panthrerina $X P \mathrm{~g}$ (B) } & $(.02)$ & $(.02)$ & - & - & - & - \\
\hline \multicolumn{2}{|c|}{ Paxillus sp. } & (.32) & (.32) & - & - & - & - \\
\hline \multicolumn{2}{|c|}{ Paxillus sp. XPg (A) } & - & - & (.69) & $(.69)$ & - & - \\
\hline \multicolumn{2}{|c|}{ Paxillus sp. X Pg (B) } & - & - & - & - & - & - \\
\hline
\end{tabular}

${ }^{*} r R f=$ relative distance of inhibition spot in relation to the distance of fluorescent spot presented by the extract of $P$. glehnii (B), which was detected closer to the front line (see text for calculation of these values).

**(A) and (B) see text.

extract of the inoculated seedling. Duchesne et al. (1988b) observed that sporulation of $F$. oxysporwn was depressed by $P$. involutus and this suppression was more pronounced when the exudate of Pinus resinosa was added, suggesting that the presence of root exudate can stimulate synthesis of antimicrobial substances produced by ectomy-corrhizal fungi. In in vitro studies, Perrin and Garbaye (1983) verified a strong suppression of Pythium ultimum, possibly as an effect of diffusible or volatile inhibitory substances produced by ectomycorrhizal fungus Hebeloma crustuliniforme.

Although we are unable to determine whether ectomycorrhizal fungi or host plant or both were responsible for the synthesis of antimicrobial compounds, the results from this study suggest that mycorrhizal association stimulated production of new fungitoxic compounds (Table 1). Laccaria laccata was able to inhibit Fusarium spp. in vitro, but production of phenolics, induced by inoculation of these ectomycorrhizal fungi might be the basis of root protection of Pseudotsuga menziesii (Sylvia and Sinclair 1993b; and Chakravarty and Hwang 1991). According to Buscot et al. (1992) not only production of 
fungistatic phenolics compounds, but also the greater vigor of mycorrhizal plants is perhaps the cause of resistance to phytopathogenic fungi. Earlier work by Stack and Sinclair (1975) showed that inoculation of Laccaria laccata spores protected $P$. menziesii against $F$. oxysporum, even without mycorrhizae.

Complementary results obtained by the paper disc technique (Table 2) suggest that some fungitoxins were also present in the aqueous extracts, and the degree of inhibition varied according to the origin of extract.

Table 2. Inhibition radius ( $r R f)^{*}$ of Fusarium roseum, Pythium sp., and Rhizoctonia solani, when extracts equivalent to 10 and $20 \mathrm{mg}^{\text {*** }}$ of mycelia or plant material (p.m.) (dry weight basis) were applied using paper disc technique.

\begin{tabular}{|c|c|c|c|c|c|c|c|}
\hline \multirow[t]{2}{*}{ Samples } & \multirow{2}{*}{$\begin{array}{l}\text { Fungus --> } \\
\text { p.m. (mg) --> }\end{array}$} & \multicolumn{2}{|c|}{ Pythium sp. } & \multicolumn{2}{|c|}{$F$. roseum } & \multicolumn{2}{|c|}{ R. solani } \\
\hline & & 10 & $20^{* *}$ & 10 & $20^{* *}$ & 10 & $20^{* *}$ \\
\hline & & ........ & 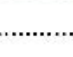 & …........ & …..... & (n.............. & ............ \\
\hline \multicolumn{2}{|c|}{$P$, glehnii $(\mathrm{Pg})\left(\mathrm{A}^{* * *}\right)$} & - & - & - & - & - & - \\
\hline \multicolumn{2}{|c|}{ P. glehnii $\left(\mathrm{B}^{*+*}\right)$} & 4.0 & 4.5 & - & 1.12 & 1.37 & 1.75 \\
\hline \multicolumn{2}{|c|}{$P$. tinctorius } & 5.0 & 5.0 & 1.0 & 1.37 & 2.0 & 2.25 \\
\hline \multicolumn{2}{|c|}{$P$. tinctorius $X P_{g}(\mathrm{~A})$} & - & - & - & - & - & - \\
\hline \multicolumn{2}{|c|}{$P$. tinctorius $X P \mathrm{~g}(\mathrm{~B})$} & 3.87 & 4.25 & 1.5 & 1.5 & 1.25 & 1.50 \\
\hline \multicolumn{2}{|c|}{ S. flavidum } & 3.87 & 4.0 & - & - & - & - \\
\hline \multicolumn{2}{|c|}{ S. flavidum $X P \mathrm{~g}(\mathrm{~A})$} & - & - & - & - & - & - \\
\hline \multicolumn{2}{|c|}{ S. flavidum $X P_{\mathrm{g}}(\mathrm{B})$} & - & - & - & - & - & - \\
\hline \multicolumn{2}{|c|}{ A. panthrerina } & 5.0 & 5.0 & 1.25 & 2.0 & 2.25 & 3.12 \\
\hline \multicolumn{2}{|c|}{ A. panthrerina $X P g(\mathrm{~A})$} & - & - & - & - & - & - \\
\hline \multicolumn{2}{|c|}{ A. panthrerina $X P g(B)$} & - & - & - & - & - & - \\
\hline \multicolumn{2}{|c|}{ Paxillus sp. } & 3.25 & 3.75 & - & 1.0 & - & - \\
\hline \multicolumn{2}{|c|}{ Paxillus sp. X Pg (A) } & - & - & - & - & - & - \\
\hline \multicolumn{2}{|c|}{ Paxillus sp. $X P g(\mathrm{~B})$} & - & - & - & - & - & - \\
\hline
\end{tabular}

$*_{r R f}=$ radius of inhibition/radius of paper disc: **This value was $13.8,16.3$ and 11.8 for $P$. tinctorius, $S$. flavidum and Paxillus sp., respectively.

***(A) and (B) see text

P. glehnii could produce antimicrobial compounds in the absence of ectomycorrhizal fungi (Table 2). Since these compounds were not detected when the plant was associated with ectomycorrhizal fungi, it is speculated that the mycosymbionts degraded these compounds or transformed them into other metabolite(s). 
The growth of $R$. solani was not affected by any EtOAc fraction tested. However, the water fraction presented some compounds that delayed pathogenic mycelial growth. No antagonistic effect on the growth of $R$. solani was observed when A. pantherina or P. tinctorius were confronted on the PDA media (Zhao et al. 1989). Kope and Fortin (1989) verified that $P$. tinctorius cell free media showed high inhibition against $R$. pra-ticola, but such inhibition was very low against $R$. solani (Kope and Fortin 1989). Although the methodologies used to test inhibition by Zhao et al. (1989) and Kope and Fortin (1989) differed from those used in this study, sensitivity of $R$. solani to compounds produced by ectomycorrhizal fungi seems very low especially in comparison with Pythium (Table 2).

The results of this study although not field tested suggest that inoculation of ectomycorrhizal fungi even when the association with the host plant is not established, may protect plants from pathogenic fungi by production of antibiotic substances. It was also verified that new antimicrobial compounds are produced directly by the ectomycorrhizal fungi or by the host plant in response to mycosymbiont association as reported by Zak (1964) and Marx (1973) for other mycorrhizal systems. Further research is needed : to detect whether these fungistatic compounds are produced in the field; and to monitor whether these ectomycorrhizal fungi are still able to protect plants against pathogenic fungi tested when they are interacting with other microorganisms (Krupa et al 1973; Schisler and Linderman 1989; and Chen et al. 1988) or with different environmental conditions (Harley and Smith 1983).

\section{ACKNOWLEDGEMENTS}

The authors sincerely thank R.M.C. Muchovej for her invaluable suggestions as well as for improving the English, and to CNPq (Conselho Nacional de Desenvolvimen-to Cientifico e Tecnologico - BRAZIL) for the scholarship granted to the first author.

\section{REFERENCES}

Buscor, F, G. WEBER and F. OBERWINKLER. 1992. Interactions between Cylindrocarpon destructans and ectomycorrhizas ofPicea abies with Laccaria laccata and Paxillus involutes. Trees, 6: 83-90.

CHAKRAVARTY, P. and S.F. HWANO. 1991. Effect of an ectpmycorrhizal fungus, Laccaria laccata, on Fusarium damping-off in Pinus banksiana seedlings. Eur. J. For. Path., 21:97-106.

CHAKRAVARTY, P. and T. UNESTAN. 1978a. Mycorrhizal fungi prevent disease in stressed pine seedlings. J. Phytopathology, 188: 355-340.

CHAKRAVARTY, P. and T. UNESTAN. 1987b. Differential influence of ectomycorrhizae on plant growth and disease resistance in Pinus sylvestris seedlings. J. Phytophatology, 120: 104-120. 
DUCHESNE, L.C., R.L. PETERSON and B.E. ELUS. 1987. The accumulation of plant-produced antimicrobial compounds in response to ectomycorrhizal fungi: a review. Phytoprotection, 68: 17-27.

DUCHESNE, L.C., R.L. PETERSON and B.E. ELUIS. 1988a. Interaction between the ectomycorrhizal fungus Paxillus involutes and Pinus resinosa induces resistance to Fusarium oxysporum. Can. J. Bot., 66: 558-562.

DUCHESNE, L.C., R.L. PETERSON and B.E. ELLIS. 1988b. Pine root exudate stimulate the synthesis of antifungal compounds by the ectomycorrhizal fungus Paxillus involutus. New Phytol., 108: 471- 476.

DUCHESNE, L.C., R.L. PETERSON and B.E. ELLIS. 1989a. The time course of disease suppression and antibiosis by the ectomycorrhizal fungus Paxillus involutus. New Phytol., Ill: 693- 698.

DUCHESNE, L.C., R.L. PETERSON and B.E. ELLIS. 1989b. The future of ectomycorrhizal fungi as biological control agents. Phytoprotection, 70: 51-57.

HARLEY, J.L. and S.E. SMITH. 1983. Mycorrhizal symbiosis. New York, Academic Press Inc., 483 p.

HomANS, A.L. and A. FUCHS. 1970. Direct bioautography on thin layer chromatograms as a method for detecting fungitoxic substances. J. Chromatog., 51: 327-329.

KOPE, H.H. and J.A., FORTIN. 1989. Inhibition of phytopathogenic fungi in vitro by cell free culture media of ectomycorrhizal fungi. New Phytol., 113: 57-63.

KOTTKE, I., M. GUTTENBERGER, R. HAMP and F. OBERWiNKLER. 1987. An in vitro method for establishing mycorrhizae on coniferous tree seedlings. Trees, 1: 191-194.

MARX, D.H. 1969. The influence of ectrotophic mycorrhizal fungi on the resistance of pine roots to pathogenic infection. I. Antagonism of fungi to root pathogenic fungi and soil bacteria. Phytopathology, 59: 153-163.

MARX, D.H. 1973. In: MARKS, G.C. and KOZLOWSKI(eds.). Ectomycorrhizae: their ecology and physiology. Academic Press, New York. Pages 351-382.

PERRIN, R. and J. GARBAYE. 1983. Influence of ectomycorrhizae on infectivity of Fyf/z/wm-infested soils and substrates. Plant and Soil, 71: 345-351.

SAMPANGI, R. and R. PERRIN. 1986. Attempts to elucidate the mechanisms involved in the protective effect of Laccaria laccata against Fusarium oxysporum. In : Gianinazzi-Pearson and S. Gianinazzi (eds), Proceedings of the 1st European symposium on mycorrhizae. Dijon, France, July 1-5, 1985. p. 799-806.

SCHISLER, D.A. and R.G. LINDERMAN. 1989, Response of nursery soil microbial populations to volatilize purge from soil around douglas-fir ectomycorrhizae. Soil Biol. Biochem., 21: 397-401.

SINCLAIR, W.A., D.M. SYLVIA and A.O. LARSEN. 1982. Disease suppression and growth promotion in douglas-fir seedlings by the ectomycorrhizal fungus Laccaria laccata. For, Sci., 28: 191-201.

STACK, R.W. and W.A. SINCLAIR. 1975. Protection of douglas-fir seedlings against Fusarium root rot by a mycorrhizal fungus in the absence of mycorrhizal formation. Phytopathology, 65: 468- 472.

SYLVIA, D.M. and W.A. SINCLAIR. 1983a. Suppressive influence of Laccaria laccata on Fusarium oxysporum and douglas-fir seedlings. Phytopathology, 73: 384-389.

SYLVIA, D.M. and W.A. SINCLAIR. 1983b. Phenolics compounds and resistance to fungal pathogens induced in primary roots of douglas-fir seedlings by the ectomycorrhizal fungus Laccaria laccata. Phytopathology, 73: 390-397.

ZHAO, Z.P., Kuo S.C. and Bi. K.C. 1989. Selection of ectomycorrhizal fungi with resistance to Rhizoctonia solani. Agriculture, Ecosystems and Environments, 28: 575-579.

ZAK, B. 1964. Role of mycorrhizae in root disease. Ann. Rev. Phytopath., 2: 377-392. 